\title{
RỐI LOẠN NHỊP NHĨ Ở BỆNH NHÂN THÔNG LIÊN NHĨ: TỈ LẸ MẮC BỆNH, DIỄN BIẾN, TIÊN LƯợNG VÀ CHỈ ĐỊNH ĐIỀU TR!
}

\section{TÓM TẮT}

RLNNtrong bệnh TLN bao gồm: rung nhĩ, cuồng nhĩ và nhịp nhanh nhĩ. Tỉ lệ mắc bệnh tăng theo tuổi, sự khác biệt có ý nghĩa thống kê ở độ tuổi 40. Đường kính nhĩ trái, mức độ hở van hai lá và mức độ hở van ba lá là những yếu tố tiên lượng của RLNN. Mặc dù RLNN giảm đi sau khi đóng TLN bằng can thiệp hoặc phẫu thuật, có thể xuất hiện rối loạn nhịp mới với thời gian theo dõi lâu dài.Phẫu thuật Maze với mục đích điều trị hoặc dự phòng rối loạn nhịp giúp làm giảm nguy cơ nhồi máu não và biến chứng chảy máu do thuốc chống đông. Các bằng chứng khoa học cho thấy RLNN nên được chẩn đoán xác định trước mổ. Phẫu thuật Maze nên được kết hợp với đóng TLN đem lại hiệu quả điều trị toàn diện cho bệnh nhân.

Tù khóa: thông liên nhĩ, rối loạn nhịp nhĩ, rung nhĩ, nhồi máu não, phẫu thuật Maze

\section{SUMMARY}

Atrial fibrillation, atrial flutter and atrial tachycardia are the most common atrial arrythmias in ASD patients. Age was a risk factor, and the incidence was significantly increased in patients over 40 years. Left atrial dimension, mitral and tricuspid regurgitation were prognosis factors. Even though the risk decreased after surgical or percutaneous closure of the ASD, recurrent arrythmia may appear after long follow-up time. The Maze procedure for treating or preventing atrial arrythmias may help lower the incidence of stroke and bleeding due to anticoagulant agents postoperatively. Clinical evidences proved that diagnosis of atrial arrythmia shoud be confirmed preoperatively in ASD patients. Maze procedure in combination with ASD closure operation was an efficient treatment for those patients.

Keywords: Atrial septal defect, atrial arrythmia, atrial fibrillation, stroke, Maze procedure.

\section{I. ĐẶT VẤN ĐỂ}

Rối loạn nhịp nhĩ (RLNN) bao gồm: cuồng nhĩ và rung nhĩ là những biến chứng thường gặp nhất ở những bệnh nhân thông liên nhĩ (TLN) trưởng thành. Chúng có thể để lại những di chứng nặng nề do biến chứng nhồi máu não, hoặc chí ít là những cơn thiếu máu não thoáng qua $[1,2]$. Thời gian gần đây đã có ngày càng nhiều nghiên cứu liên quan đến vấn đề này và đã có một số quan điểm được đưa ra về cách thức điều trị RLNN ở bệnh nhân TLN[3, 4].

\section{RỐI LOẠN NHỊP NHĨ TRƯớC CAN} THIỆP VÀ PHẪU THUẠT

RLNN (cuồng nhĩ, rung nhĩ, và nhịp nhanh nhĩ) là những biến chứng thường gặp ở bệnh nhân trưởng thành mắc TLN [1]. Tỉ lệ phát hiện RLNN ở bệnh nhân TLN trước mổ khác nhau tùy theo từng nghiên cứu và phương pháp chẩn đoán. Theo Gatzoulis cùng cộng sự (1999) [5], tỉ lệ RLNN trước mổ là $19 \%$ trong khi theo Berger cùng cộng sự (1999) [3], tỉ lệ này là $27 \%$.

Ít nghiên cứu quan tâm tới RLNN cơn. Trong nghiên cứu của mình, Brandenburg cùng cộng sự (1983) thấy loại rối loạn nhịp này không phải ít gặp, với tỉ lệ 14\%[6].

\subsection{Các yếu tố nguy co}

Trong một nghiên cứu trên 286 bệnh nhân

* Bệnh viện đa khoa Đà Nã̃ng

** Trung tâm Tim mạch Bệnh viện E

Ngườ chịu trách nhiệm khoa học: BS Đặng Quang Huy

Ngày nhận bài: 01/11/2019 - Ngày Cho Phép Đăng: 20/12/2019

Phản Biện Khoa học: PGS.TS. Đặng Ngọc Hùng GS.TS. Lề Ngoc Thành 
TLN, Oliver cùng cộng sự thấy rằng tuổi của bệnh nhân tại thời điểm phẫu thuật, áp lực ĐMP, đường kính thất phải, đường kính nhĩ trái, mức độ hở van hai lá (VHL), và mức độ hở van ba lá (VBL) là những yếu tố nguy cơ làm xuất hiện rung nhĩ ở bệnh nhân TLN (bảng 1)[7].

Bảng 1: Phân tích đơn biến và đa biến về các yếu tố nguy cơ của rung nhĩ ở 286 bệnh nhân thông liên nhĩ [7]

\begin{tabular}{|c|c|c|c|c|}
\hline Biến số & $\begin{array}{c}\text { Rung nhĩ } \\
\text { n=43 (15\%) }\end{array}$ & $\begin{array}{l}\text { Nhịp xoang } \\
\text { n=243 (85\%) }\end{array}$ & $\begin{array}{l}\text { Giá trị p } \\
\text { Đơn biến }\end{array}$ & $\begin{array}{l}\text { Giá trị p } \\
\text { Đa biến }\end{array}$ \\
\hline Tuổi tại thời điểm phẫu thuật & $60 \pm 16$ & $36 \pm 17$ & $<0,001$ & 0,001 \\
\hline Nũ (\%) & 67 & 65 & 0,76 & -- \\
\hline TLN lỗ thứ phát (\%) & 77 & 69 & 0,27 & -- \\
\hline Đường kính TLN (mm) & $25 \pm 11$ & $22 \pm 7$ & 0,34 & -- \\
\hline $\mathrm{Qp} / \mathrm{Qs}$ & $2,9 \pm 0,9$ & $2,7 \pm 0,8$ & 0,15 & -- \\
\hline Đường kính thất phải (mm) & $36 \pm 10$ & $31 \pm 10$ & 0,03 & 0,06 \\
\hline Áp lực tâm thu ĐMP (mmHg) & $46 \pm 17$ & $38 \pm 18$ & $<0,001$ & 0,68 \\
\hline Đường kính nhĩ trái (mm) & $57 \pm 10$ & $41 \pm 8$ & $<0,001$ & 0,001 \\
\hline Tỉ lệ co ngắn thất trái (\%) & $33 \pm 8$ & $35 \pm 6$ & 0,20 & -- \\
\hline Mức độ hở van hai lá (0-3) & $1,6 \pm 0,9$ & $0,8 \pm 0,8$ & $<0,001$ & 0,001 \\
\hline Mức độ hở van ba lá (0-3) & $2,1 \pm 0,8$ & $1,1 \pm 0,6$ & $<0,001$ & 0,04 \\
\hline
\end{tabular}

\subsection{1. Đường kính nhĩ trái:}

Nguy cơ xuất hiện rung nhĩ tăng tỉ lệ thuận với đường kính nhĩ trái (hình 1)[8]. Đường kính nhĩ trái $>45 \mathrm{~mm}$ được xác định là yếu tố nguy cơ xuất hiện rung nhĩ trước mổ ở bệnh nhân TLN ( $\mathrm{p}<0,001)$ [9].Trong bệnh TLN, nhĩ trái giãn có thể là hậu quả của dòng máu qua lỗ TLN; ngoài ra chức năng tâm trương của thất trái, thất phải và mức độ hở VHL cũng là những yếu tố liên quan [10]. Các rối loạn nhịp nhĩ kéo dài mà chủ yếu là rung nhĩ cũng được xác định là yếu tố gây giãn nhĩ trái [11].

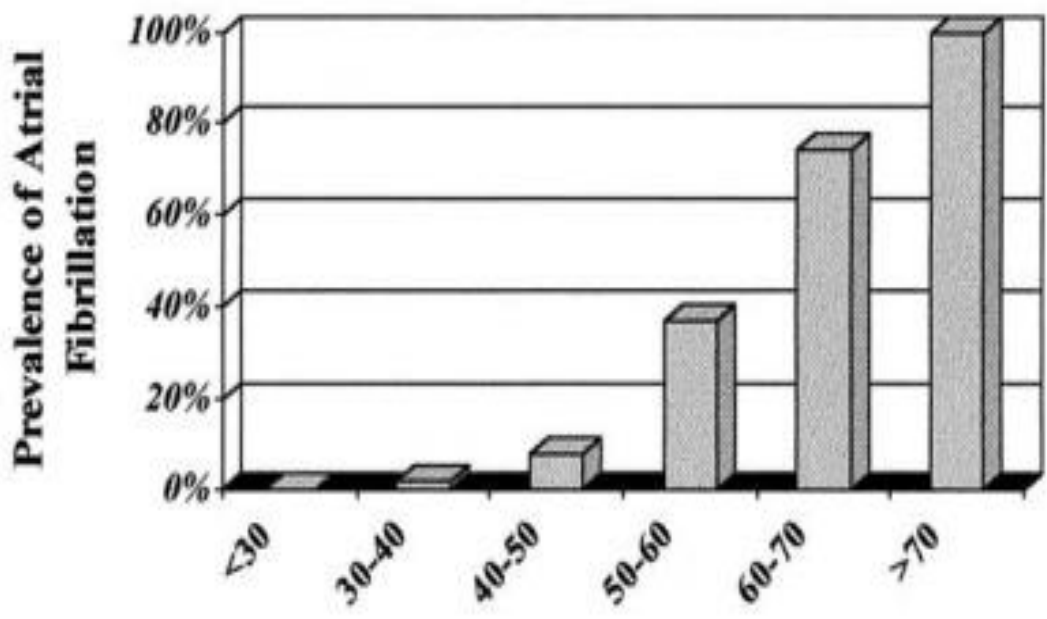

Left atrial dimension (mm)

Hình 1. mối liên hệ giữa đường kính nhĩ trái và tỉ lệ rung nhĩ ở bệnh nhân thông liên nhĩ [7] 
2.1.2. Độ tuổi xuất hiện rối loạn nhịp nhĩ:

Tỉ lệ xuất hiện RLNN ở bệnh nhân TLN tăng theo tuổi (hình 2)[7]. Theo Nyboe cùng cộng sự (2012), tỉ lệ mắc rung nhĩ ở nhóm bệnh nhân từ 18 đến 50 tuổi là $6 \%$ trong khi đó tỉ lệ rung nhĩ ở nhóm bệnh nhân $>50$ tuổi là $47 \%[12]$. Trong nghiên cứu của Berger cùng cộng sự (1999), nhóm bệnh nhân không có RLNN có tuổi trung bình là $39 \pm 13$ tuổi - thấp hơn một cách có ý nghĩa với nhóm bệnh nhân cuồng nhĩ và rung nhĩ (tuổi trung bình lần lượt là $54 \pm 12$ tuổi và $59 \pm 8$ tuổi, $\mathrm{p}=0,0001)[3]$.

Trong nhiều nghiên cứu, các tác giả thống nhất 40 tuổi là điểm cut-off. Theo đó, tỉ lệ rung nhĩ ở nhóm bệnh nhân > 40 tuổi cao hơn một cách có ý nghĩa so với nhóm bệnh nhân $<40$ tuổi $[5,7]$.

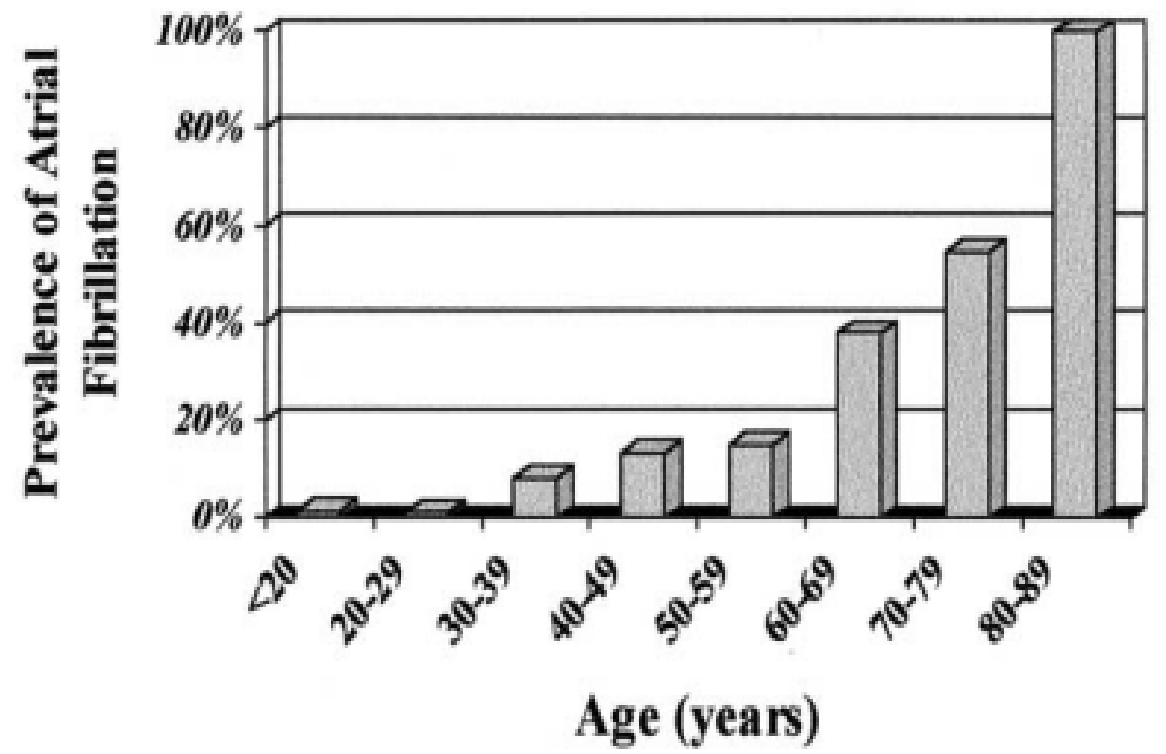

Hình 2. Mối liên hệ giũa tuổi và tỉ lệ rung nhĩ ở bệnh nhân thông liên nhĩ[7]

\begin{abstract}
2.1.3. Loại rối loạn nhịp nhĩ xuất hiện ở tù̀ng nhóm tuổi:

Trong nghiên cứu được thực hiện ở Berlin (1999), tác giả chia các đối tượng nghiên cứu theo nhóm tuổi và ghi nhận tình trạng RLNN ở từng nhóm tuổi đó. Ở nhóm bệnh nhân $<40$ tuổi tỉ lệ RLNN chỉ là $2 \%$ bao gồm cuồng nhĩ và ngoại tâm thu nhĩ. Ở nhóm bệnh nhân có độ tuổi trung bình (40-60), tỉ lệ bệnh nhân bị cuồng nhĩ và rung nhĩ trước mổ là như nhauchiếm $15 \%$. Trong khi đó ở nhóm bệnh nhân già hơn $(>60$ tuổi), rung nhĩ chiếm đa số với tỉ lệ $61 \%$ so với tỉ 1ệ $19 \%$ của cuồng nhĩ (bảng 2)[3].
\end{abstract}

\subsubsection{Mức độ hở van hai lá:}

Hở VHL là thương tổn khá thường gặp trong TLN lỗ thứ phát và TLN thể xoang tĩnh mạch[13, 14]. Theo Boucher cùng cộng sự (1979), mức độ hở VHL trong bệnh TLN tăng dần theo tuổi. Mặc dù vậy, triệu chứng lâm sàng của hở VHL thường không rõ ràng, ngay cả khi hở VHL mức độ nhiều [14]. Tổn thương VHL chủ yếu gặp là tình trạng sa van do nhiều nguyên nhân: sự thay đổi về hình học của thất trái [7], thoái hóa nhầy của mô van [15], và tổn thương van dạng thấp [14]. Oliver cùng cộng sự (2002) thấy rằng có sự tương quan chặt chẽ giữa mức độ hở VHL với tỉ lệ mắc rung nhĩ với $\mathrm{RR}=3,0(95 \% \mathrm{CI} 1,6$ tới 5,8)[7]. Theo đó, tỉ lệ rung nhĩ ở bệnh nhân TLN tăng khi mức độ hở VHL tăng (hình 3). 


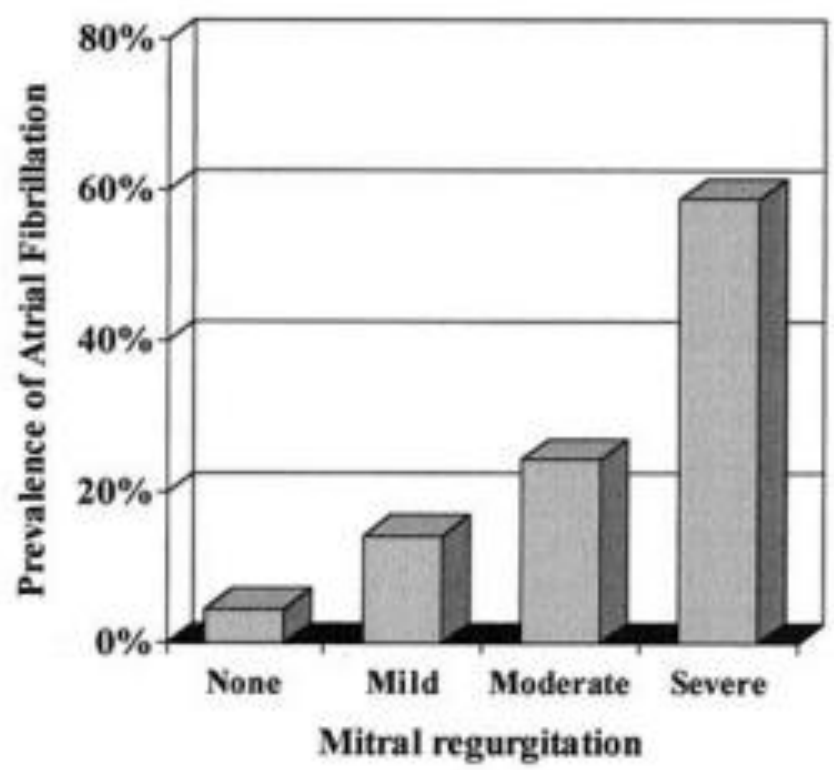

Hình 3. Mối liên hệ giũua mức độ hở van hai lá và tỉ lệ rung nhĩ ở bệnh nhân thông liên nhĩ [7]

Hynes cùng cộng sự (1974) khuyến cáo rằng hở VHL cần được sửa chữa ở bộ máy van, dưới van hoặc thu nhỏ vòng van; riêng hở VHL nhiều có nguy cơ cần thay VHL nhân tạo[15]. Hở VHL trong bệnh TLN nếu không được đánh giá đúng mức và không được xử lý sẽ có thể tồn tại sau khi đóng TLN và là yếu tố góp phần làm xuất hiện rung nhĩ mới sau mổ.

\subsubsection{Mức độ hở van ba lá:}

Hở VBL là thương tổn rất thường gặp trong bệnh TLN. Tỉ lệ hở VBL khác nhau theo từng nghiên cứu, chủ yếu phụ thuộc vào cơ cấu tuổi của bệnh nhân [16-18]. Nguyên nhân của hở VBL hầu hết là do giãn vòng van, ngoài ra có thể do bất thường cấu trúc lá van hoặc do thoái hóa nhầy. Theo Oliver cùng cộng sự (2002), mức độ hở VBL tăng làm tăng nguy cơ rung nhĩ (hình 4 ) và sửa VBL là cần thiết ngăn ngừa xuất hiện rung nhĩ mới[7].

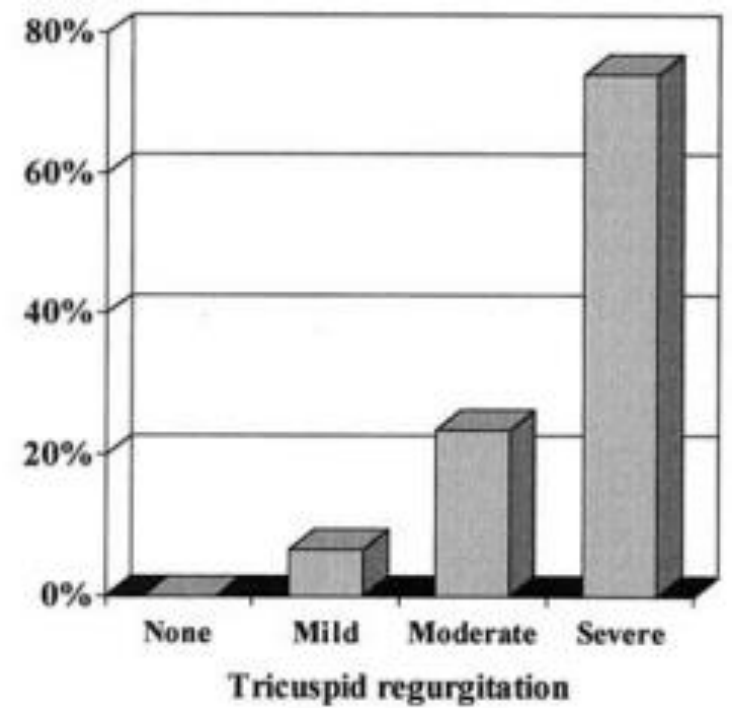

Hình 4. Mối liên hệ giũa mức độ hở van ba lá và tỉ lệ rung nhĩ ở bệnh nhân thông liên nhĩ [7] 


\section{Bảng 2: Sự khác biệt về tỉ lệ của các loại rối loạn nhịp nhĩ ở các nhóm tuổi trước và sau phẫu thuật đóng thông liên nhĩ [3]}

\begin{tabular}{|l|c|c|c|}
\hline \multicolumn{1}{|c|}{ Phân loại } & $\begin{array}{c}\mathbf{1 8 - 4 0} \text { tuổi } \\
(\mathbf{n = 1 0 1})\end{array}$ & $\begin{array}{c}\mathbf{4 0 - 6 0} \text { tuổi } \\
(\mathbf{n = 8 3})\end{array}$ & $\begin{array}{c}\text { > 60 tuổi } \\
(\mathbf{n = 2 7})\end{array}$ \\
\hline Trước phẫu thuật & & & $2(8 \%)$ \\
\hline Ngoại tâm thu nhĩ & $1(1 \%)$ & $2(2 \%)$ & $5(19 \%)$ \\
\hline Cuồng nhĩ & $1(1 \%)$ & $12(15 \%)$ & $16(61 \%)$ \\
\hline Rung nhĩ & $0(0 \%)$ & $12(15 \%)$ & \\
\hline Ngay sau phẫu thuât & & & $10(39 \%)$ \\
\hline Cuồng nhĩ & $17(17 \%)$ & $23(28 \%)$ & $15(58 \%)$ \\
\hline Rung nhĩ & $2(2 \%)$ & $14(17 \%)$ & \\
\hline Sau phẫu thuật muộn & & & $3(11 \%)$ \\
\hline Cuồng nhĩ & $0(0 \%)$ & $7(9 \%)$ & $13(48 \%)$ \\
\hline Rung nhĩ & $0(0 \%)$ & $8(10 \%)$ & \\
\hline
\end{tabular}

2.2. Diễn biến của rối loạn nhịp nhĩ sau đóng lỗ thông:

Cuồng nhĩ xuất hiện ở bệnh nhân TLN có thể do: (1) nhĩ phải giãn, (2) tăng áp lực trong nhĩ phải [6], và (2) đường dẫn truyền bị cản trở [19]. Đó là lý do tỉ lệ cuồng nhĩ có thể giảm đi sau khi các nguyên nhân như nhĩ phải giãn, tăng áp lực trong nhĩ phải giảm đi sau khi lỗ thông được đóng kín [6, 19].

Rung nhĩ được tạo ra do những vòng vào lại tại nhĩ với số lượng có thể rất lớn [6]. Rung nhĩ mạn tính là hậu quả của những biến đổi ở cơ nhĩ, đó là lý do khiến rung nhĩ khó trở về nhịp xoang hơn so với cuồng nhĩmặc dù lỗ TLN được đóng[20].

Trong nghiên cứu của Berger cùng cộng sự (1999),có sự khác biệt rõ về tiên lượng giữa cuồng nhĩ và rung nhĩ sau khi đóng TLN. Có $55 \%$ bệnh nhân cuồng nhĩ trước mổ chuyển về nhịp xoang với thời gian theo dõi muộn, trong khi đó tỉ lệ này là $12 \%$ ở bệnh nhân rung nhĩ trước mổ $(p<0,04)$ [3]. Kết luận này cũng được công nhận bởi Silverside cùng cộng sự với thời gian theo dõi trung bình 17 tháng[21].

Nhiều tác giả công nhận hiệu quả của đóng TLN (bằng can thiệp hoặc phẫu thuật) trong việc làm giảm tỉ lệ rung nhĩ sau mổ với thời gian theo dõi ngắn hạn tới trung hạn (< 5 năm)[22].Trong một nghiên cứu thực hiện ở Toronto năm 1999, $40 \%$ bệnh nhân rung nhĩ trở thành nhịp xoang sau đóng lỗ thông với thời gian theo dõi 3 năm [5]. Tuy nhiên sau 5 năm hiệu quả của việc đóng TLN trong chuyển nhịp giảm dần $[12,22]$.

Brandenburg cùng cộng sự (1983) nghiên cứu trên nhóm bệnh nhân TLN từ 44 tuổi trở lên bị RLNN cơn (rung nhĩ, cuồng nhĩ, và nhịp nhanh trên thất) với thời gian theo dõi trung bình 12 năm. Không có sự khác biệt về tuổi, giới, áp lực ĐMP, áp lực NP trước mổ, kích thước dòng shunt, kích thước nhĩ phải, và thời gian theo dõi. Trong nhóm rung nhĩ cơn, $88 \%$ bệnh nhân có tần suất xuất hiện cơn rung nhĩ dày hơn hoặc trở thành rung bĩnh bền bỉ sau mổ. Hơn $44,4 \%$ bệnh nhân có cơn nhịp nhanh trên thất trước mổ không mất đi sau mổ. Cuồng nhĩ cơn trước mổ cũng có thể trở thành rung nhĩ bền bỉ sau mổ [6]. Tỉ lệ trở về nhịp xoang trong nghiên cứu này thấp có thể do độ tuổi của bệnh nhân trong nghiên cứu này cao (từ 44 tuổi trở lên).

\subsection{Rung nhĩ mới xuất hiện sau đóng lỗ thông}

RLNN xuất hiện sau mổ không chỉ do những thay đổi cấu trúc ở thành nhĩ từ trước mổ mà còn do những sẹo mới hình thành ở thành nhĩ trong quá trình phẫu thuật[23].Sẹo mổ dọc rãnh 
nhĩ thất có thể tạo thành vòng vào lại quanh nó dục[25]. Henglein cùng cộng sự (1999) đề xuất [24]. Có 3 vòng vào lại có thể xuất hiện sau mổ: đường mở nhĩ phải mới theo chiều dọc tới rãnh vòng thứ nhất quanh đường mở nhĩ phải, vòng thứ 2 Waterson có tác dụng cắt đứt vòng vào lại quanh quanh vòng VBL, và vòng thứ 3 quanh hố bầu vòng VBL (hình 5) [25].

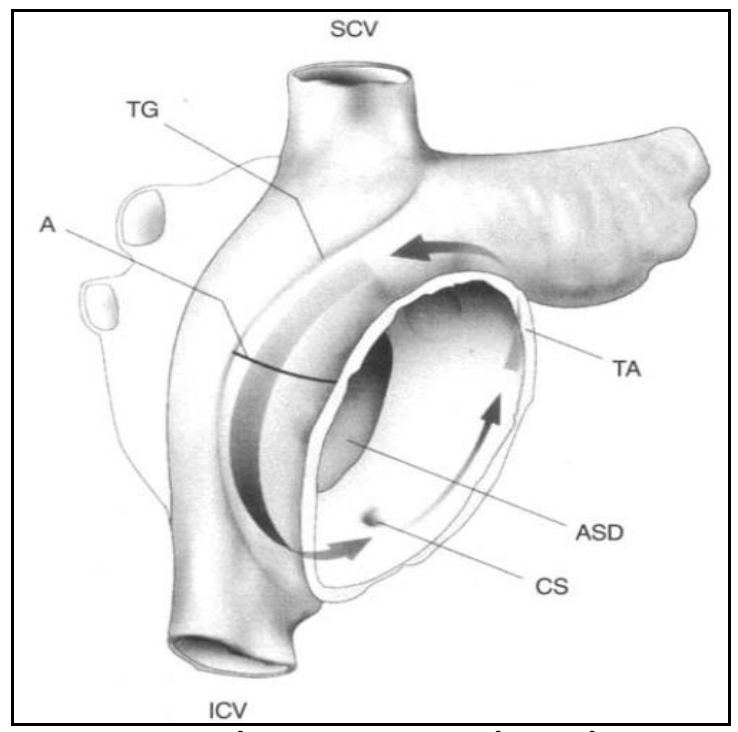

Hình 5: Vòng vào lại hình thành theo chiều ngược kim đồng hồ quanh vòng van ba lá. A: đương mổ được đề xuất để cắt đứt vòng vào lại [25]

Ngoài ra vị trí đặt ống thông TMC dưới cũng có thể tạo thành một vùng dẫn truyền chậm sau mổ. Vùng dẫn truyền chậm này cũng có thể xuất hiện ngay trên hoặc dưới vị trí đặt ống thông TMC dưới (hình 6) [23].

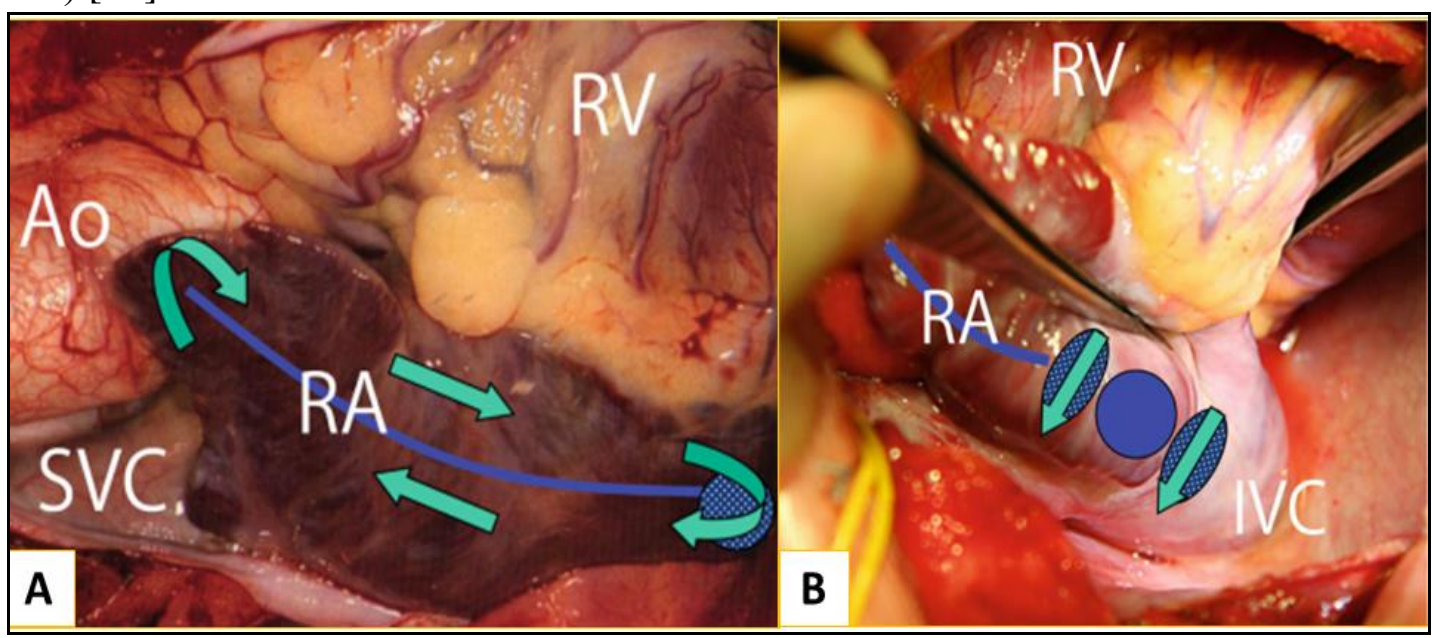

Hình 6: Nhũng vòng vào lại và vùng dẫn truyền chậm có thể xuất hiện sau mổ [23]

Trong nghiên cứu của Berger cùng cộng sự (1999), tỉ lệ xuất hiện cuồng nhĩ mới cao một cách có ý nghĩa so với rung nhĩ mới ở tất cả các nhóm tuổi (bảng 2). Mặc dù vậy, tỉ lệ các loại rối loạn nhịp đều giảm so với trước mổ với thời gian theo dõi lâu dài [3].

Tỉ lệ xuất hiện rung nhĩ mới bị chi phối bởi 2 yếu tố: tuổi của bệnh nhân tại thời điểm phẫu thuật/ can thiệp và thời gian theo dõi sau đóng TLN. Tuổi của bệnh nhân càng cao và thời gian theo dõi càng 
lâu thì tỉ lệ rung nhĩ mới xuất hiện càng cao.Nyboe cùng cộng sự (2015) nghiên cứu trên đối tượng bệnh nhân trưởng thành (>18 tuổi), công bố $21 \%$ bệnh nhân sau đóng TLN xuất hiện rung nhĩ mới với thời gian theo dõi trung bình 9,6 năm[2].

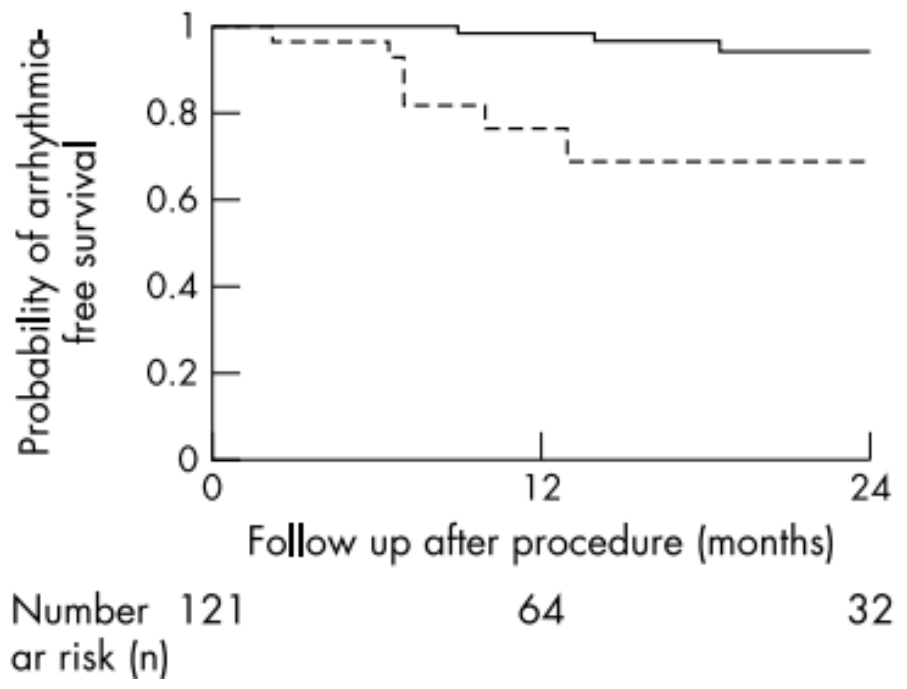

Hình 7: Kaplan-Meier về mắc rung nhĩ mới sau đóng thông liên nhĩ [21]

Bệnh nhân < 55 tuổi tại thời điểm can thiệp/ phẫu thuật đóng thông liên nhĩ (đường liên tục) có khả năng không mắc rung nhĩ mói cao hơn so với bệnh nhân $\geq 55$ tuổi (đường gián đoạn), $p<0,001$.

Silversides cùng cộng sự (2004)xác định 55 tuổi là mốc tuổi có sự khác biệt có ý nghĩa thống kê về tỉ lệ mắc mới rung nhĩ với $\mathrm{p}<0,001$ (hình 7)[21]. Theo một nghiên cứu tại Mayo clinic về những bệnh nhân được phẫu thuật đóng lỗ TLN đơn thuần với thời gian theo dõi từ 27 đến 32 năm, những bệnh nhân được phẫu thuật sau 40 tuổi có $59 \%$ trường hợp xuất hiện rung nhĩ hoặc cuồng nhĩ trong thời gian theo dõi. Trong khi tỉ lệ này là $41 \%$ ở nhóm bệnh nhân được phẫu thuật ở khoảng tuổi 25-40 mặc dù chỉ có 6\% bệnh nhân có rối loạn nhịp nhĩ trước mổ [26].

Đa số tác giả ủng hộ quan điểm "bệnh nhân được phẫu thuật sớm sẽ giúp ngăn ngừa tiến triển rung nhĩ mới sau đóng TLN". Có nhiều báo cáo lâm sàng đưa ra những giới hạn tuổi khác nhau. Gatzoulis cùng cộng sự (1999) cho rằng bệnh nhân nên được can thiệp/ phẫu thuật trước 40 tuổi để ngăn ngừa xuất hiện rung nhĩ muộn [5].

Lý tưởng hơn, nhiều tác giả khuyến cáo bệnh nhân nên được đóng TLN trước tuổi 25 . Oliver cùng cộng sự (2002) kết luận rằng độ tuổi can thiệp/ phẫu thuật $<25$ là yếu tố tiên lượng độc lập về rung nhĩ sau mổ ở bệnh nhân TLN
[7].Mặc dù vậy, trong nghiên cứu của Nyboe cùng cộng sự (2015), vẫn ghi nhận rung nhĩ mới ở nhóm bệnh nhân được phẫu thuật trước 25 tuổi. Điều đó cho thấy những thay đồi về đường dẫn truyền và sự xơ hóa khoảng kẽ giữa các tế bào có thể xuất hiện sớm hơn mốc 25 tuổi[2].

\section{liên nhĩ:}

2.4. Nhồi máu não ở bệnh nhân thông

Murphy cùng cộng sự (1990) chỉ ra rằng $22 \%$ trường hợp tử vong muộn ở bệnh nhân TLN là do nhồi máu não[26].Nhồi máu não trước khi đóng kín lỗ thông chủ yếu do đảo chiều dòng shunt, rung nhĩ chỉ là nguyên nhân trong $5,4 \%-28 \%$ trường hợp $[1,2]$. Ngược lại, sau khi lỗ thông được đóng, rung nhĩ lại là nguyên nhân chính (chiếm 75-83\%) gây nhồi máu não[2, 3, 5]. Tuổi xuất hiện nhồi máu não thấp hơn và tî lệ tử vong do nhồi máu não cao hơn ở những bệnh nhân TLN so với những bệnh nhân không có TLN[2].

\subsection{Chỉ định điều trị[[23]}

Bệnh nhân TLN kèm theo rối loạn nhịp trước mổ có 3 lựa chọn điều trị:

- Can thiệp đốt nhịp, sau đó phẫu thuật 
đóng lỗ TLN

- Phẫu thuật một thì: đóng TLN kết hợp phẫu thuật điều trị rối loạn nhịp (phẫu thuật Maze một nhĩ hoặc hai nhĩ)

- Phẫu thuật đóng TLN trước, sau đó sẽ làm can thiệp đốt nhịp nếu cần thiết. Với cách tiếp cận này, một số bệnh nhân trở lại nhịp xoang sau mổ sẽ tránh phải can thiệp nhịp.

Bệnh nhân TLN không kèm theo rối loạn nhịp trước mổ có 2 lựa chọn:

- Phẫu thuật đóng TLN kết hợp cắt lạnh hoặc cắt đốt bằng sóng cao tần với mục đích dự phòng (prophylactic surgical ablation) để làm giảm tối thiểu khả năng hình thành rối loạn nhịp nhĩ sau mổ. Nguyên lý của phương pháp cắt đốt dự phòng là cắt đứt các vòng vào lại có thể hình thành sau mổ (quanh đường mở nhĩ phải, quanh vòng $\mathrm{VBL}$, và quanh hố bầu dục).

- Phẫu thuật đóng TLN trước, sau đó sẽ làm can thiệp đốt nhịp nếu cần thiết.

\subsection{Vai trò của phẫu thuật Maze:}

Nghiên cứu ở Toronto (1999) kết luận rằng việc đóng lỗ thông là không đủ để ngăn ngừa biến chứng nhồi máu não, phẫu thuật Maze có thể cần thiết[1]. Trong nghiên cứu thực hiện tại Mayo Clinic (2000), phẫu thuật Maze đã được chứng minh làm giảm tỉ lệ nhồi máu não và biến chứng chảy máu nguy hiểm liên quan tới thuốc chống đông so với nhóm chứng $(\mathrm{p}=0,04)$ (hình 8.) [27].

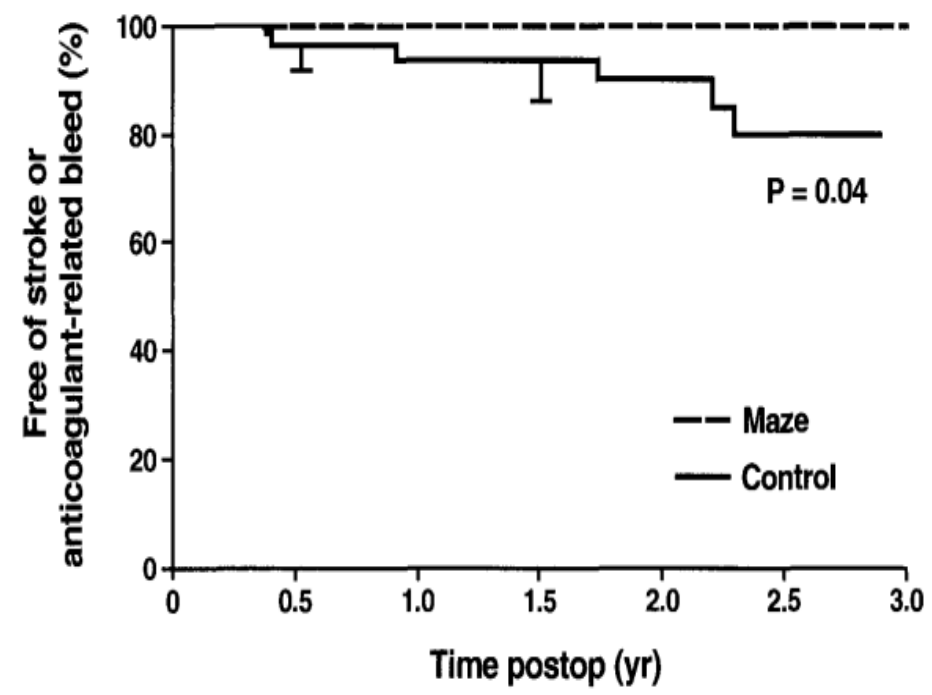

Hình 8: Kaplan-Meier về biến chứng chảy máu não và chảy máu nguy hiểm liên quan đến thuốc chống đông ở nhóm phẫu thuật Maze và nhóm chứng [27]
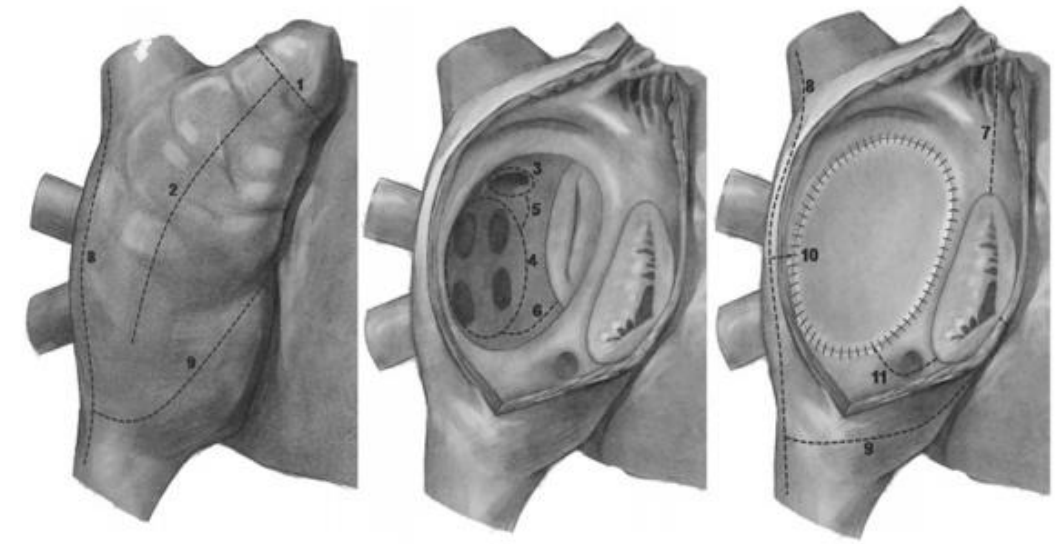

Hình 9: Phẫu thuật Maze hai nhĩ trong bệnh thông liên nhĩ [28] 
Phẫu thuật Maze chọn lọc cho một buồng nhĩ (trái hoặc phải) xuất phát từ nhận định: buồng nhĩ trái (hoặc phải) trong bệnh lý tim phải (hoặc trái) có tương đối ít thay đổi về mặt cấu trúc do tăng gánh thể tích hoặc áp lực gây ra. Do đó chỉ cần sử dụng phẫu thuật Maze riêng cho bên buồng nhĩ bị ảnh hưởng chính cũng đủ đem lại hiệu quả[28].

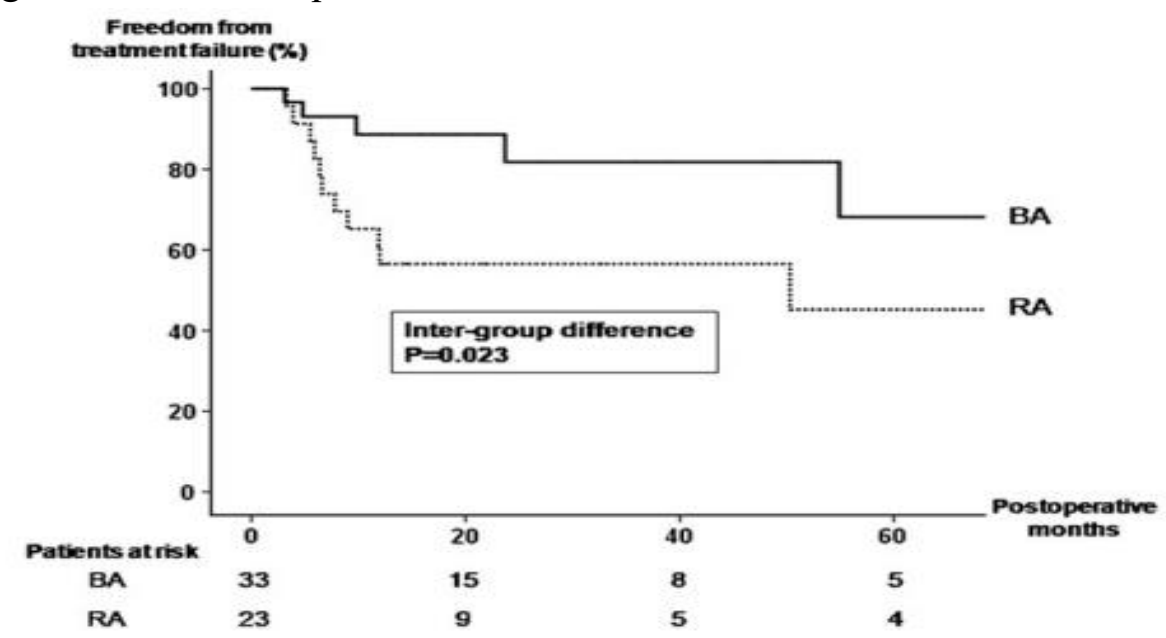

Hình 10: Kaplan-Meier về thất bại của hai loại phẫu thuật Maze [28]

Thất bại được xác định là xuất hiện rung nhĩ, cuồng nhĩ, nhịp nhanh nhĩ, hoặc phải cấy máy tạo nhịp vĩnh viễn. BA (biatrial Maze procedure): phẫu thuật Maze 2 nhĩ, RA (right atrial maze procedure): phẫu thuật Maze nhĩ phải

Tuy nhiên trong thực tế, kích thước và cấu trúc của nhĩ trái trong bệnh TLN luôn có sự biến đổi ở các mức độ nhất định[10]. Im cùng cộng sự (2013) bằng phân tích đa biến chỉ ra rằng phẫu thuật Maze nhĩ phải cho bệnh nhân TLN kèm rung nhĩ có thời gian thất bại điều trị ngắn hơn một cách có ý nghĩa thống kê so với phẫu thuật Maze hai nhĩ (tỉ lệ rủi ro: 5,11; p =0,006) (hình 10)[28].

Phẫu thuật Maze được coi là thành công khi không có rung nhĩ, cuồng nhĩ, hoặc nhịp nhanh nhĩ sau phẫu thuật 3 tháng. Nhịp bộ nối hoặc block nhĩ thất đòi hỏi phải cấy máy tạo nhịp được xem là biến chứng hơn là thất bại của phẫu thuật. Shim cùng cộng sự (2013) báo cáo 42 bệnh nhân rung nhĩ/ TLN được phẫu thuật Maze hai nhĩ với tỉ lệ tái phát rung nhĩ theo các mốc thời gian theo dõi được trình bày trong hình 11[29].

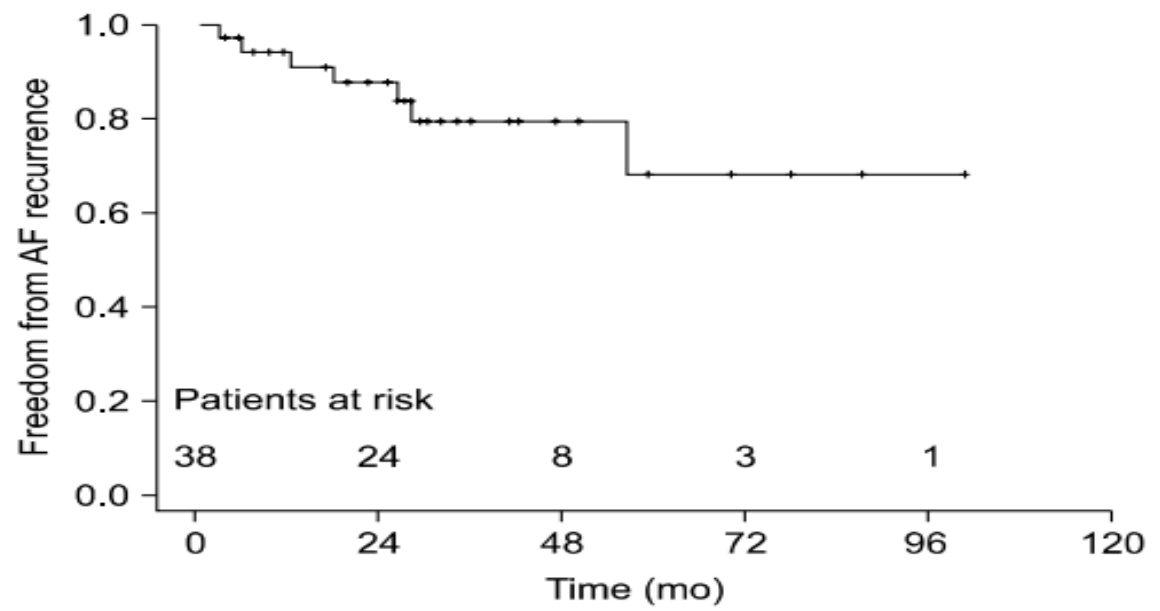

Hình 11: Kaplan-Meier về tái phát rung nhĩ sau phẫu thuật Maze hai nhĩ[29]

Tỉ lệ không tái phát rung nhĩ tại các thờ điểm khám lại sau mổ 3 tháng, 6 tháng, 1 năm, 2 năm, 3 năm và 5 năm lần luợt là $97,4 \pm 2,6 ; 94,4 \pm 3,8 ; 91,2 \pm 4,9 ; 87,8 \pm 5,8 ; 79,5 \pm 7,6 ; 68,2 \pm 12,4$ 
Trong phẫu thuật (Cox-Maze II, Cox-Maze III, Kosakai-Maze, Maze nhĩ trái, Maze nhĩ phải...), đường kính nhĩ trái trước mổ là yếu tố tiên lượng quan trọng. Đường kính nhĩ trái càng lớn thì tỉ lệ thành công của phẫu thuật Maze càng thấp[30]. Kosakai cùng cộng sự (2000) chỉ ra rằng tỉ lệ thành công của phẫu thuật Maze là $100 \%$ khi đường kính nhĩ trái thì tâm thu $<45 \mathrm{~mm}$; và khi đường kính nhĩ trái $>87 \mathrm{~mm}$ tỉ lệ thành công là $0 \%$ (hình 12) [31].

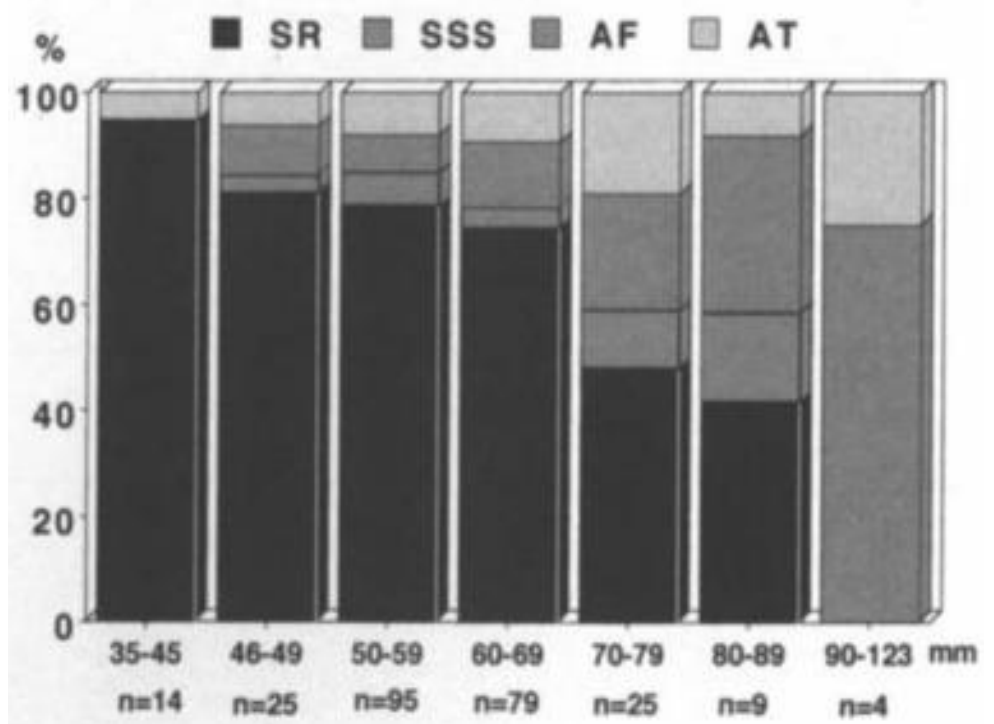

Hình 12: Mối liên quan giũa đường kính nhĩ trái trước phẫu thuật với kết quả của phẫu thuật Maze ở bệnh nhân thông liên nhĩ [31]

Trong phẫu thuật Maze, khoảng thời gian bị rung nhĩ của bệnh nhân là một yếu tố tiên lượng quan trọng. Kosakai cùng cộng sự (2000) thấy rằng: nếu thời gian bị rung nhĩ < 0,3 năm thì tỉ lệ thành công của phẫu thuật Maze là 100\%. Ngược lại, nếu thời gian bị rung nhĩ kéo dài $>32$ năm tỉ lệ thành công là $0 \%($ hình 13$)$ [31].

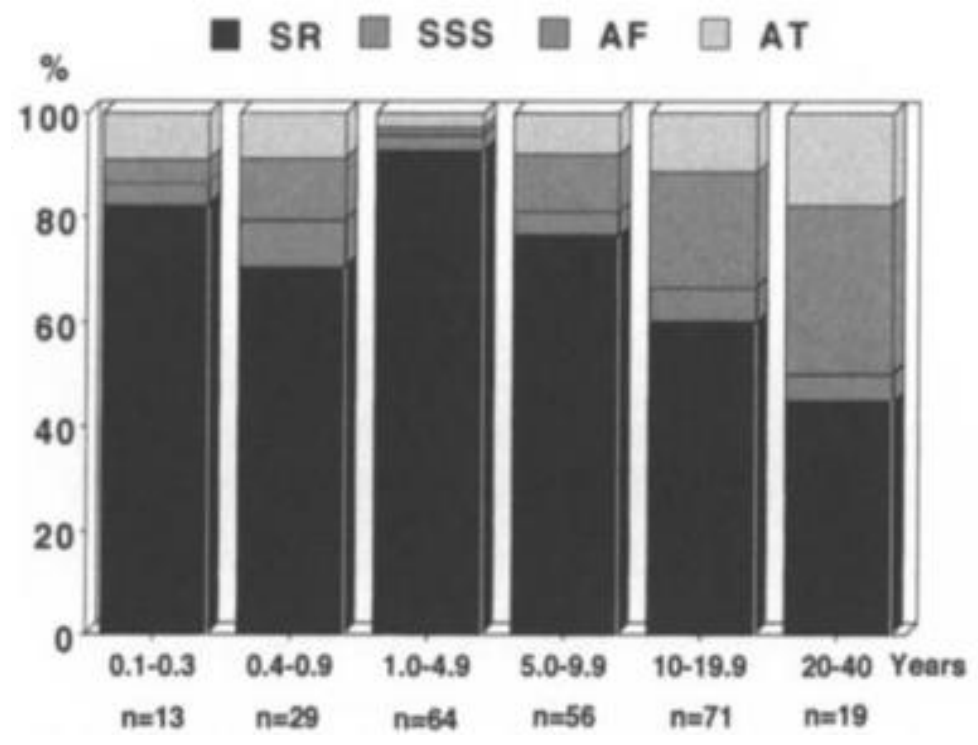

Hình 13: Mối liên quan giữa khoảng thời gian bị rung nhĩ với kết quả của phâ̂u thuật Maze ở bệnh nhân thông liên nhĩ[31] 


\section{KẾT LUẬN}

RLNN trong bệnh TLN bao gồm: rung nhĩ, cuồng nhĩ và nhịp nhanh nhĩ. Tỉ lệ mắc bệnh tăng theo tuổi, sự khác biệt có ý nghĩa thống kê ở độ tuổi 40. Đường kính nhĩ trái, mức độ hở van hai lá và mức độ hở van ba lá là những yếu tố tiên lượng của RLNN.

Đóng TLN bằng can thiệp/ phẫu thuật có hiệu quả cao trong việc chuyển nhịp ở bệnh nhân cuồng nhĩ, hiệu quả kém hơn ở bệnh nhân rung nhĩ trước mổ. Hiệu quả này có tác dụng trong thời gian trung hạn $(<5$ năm). Sau 5 năm, có thể xuất hiện RLNN mới với tỉ lệ mắc, tỉ lệ biến chứng nhồi máu não, và nguy cơ tử vong cao hơn so với quần thể.

Phẫu thuật Maze kết hợp đóng TLN có thể được chỉ định ở bệnh nhân RLNN trước mổ hoặc mục đích dự phòng ở bệnh nhân không có RLNN trước mổ. Trong khi phẫu thuật Maze nhĩ phải nên chỉ định cho bệnh nhân cuồng nhĩ, phẫu thuật Maze hai nhĩ cần áp dụng cho bệnh nhân rung nhĩ trước mổ.

Tỉ lệ thành công của phẫu thuật Maze là rất khả quan, trung bình $68 \%$ với thời gian theo dõi 5 năm. Đường kính nhĩ trái trước phẫu thuật, thời gian bị rung nhĩ là những yếu tố ảnh hưởng tới thành công của phẫu thuật Maze.

\section{TÀI LIẸU THAM KHẢO}

1. F. Berger, M. Vogel, O. Kretschmar và các cộng sự. (2005), "Arrhythmias in patients with surgically treated atrial septal defects", Swiss Med Wkly, 135(11-12), tr. 175-8.

2. C. Nyboe, M. S. Olsen, J. E. NielsenKudsk và các cộng sự. (2015), "Atrial fibrillation and stroke in adult patients with atrial septal defect and the long-term effect of closure", Heart, 101(9), tr. 706-11.

3. F. Berger, M. Vogel, A. Kramer và các cộng sự. (1999), "Incidence of atrial flutter/fibrillation in adults with atrial septal defect before and after surgery", Ann Thorac Surg, 68(1), tr. 75-8.

4. L. I. Bonchek, M. W. Burlingame, S. J. Worley và các cộng sự. (1993), "Cox/maze procedure for atrial septal defect with atrial fibrillation: management strategies", Ann Thorac Surg, 55(3), tr. 607-10.

5. M. A. Gatzoulis, M. A. Freeman, S. C. Siu và các cộng sự. (1999), "Atrial arrhythmia after surgical closure of atrial septal defects in adults", $N$ Engl J Med, 340(11), tr. 839-46.

6. R. O. Brandenburg, Jr., D. R. Holmes, Jr., R. O. Brandenburg và các cộng sự. (1983), "Clinical follow-up study of paroxysmal supraventricular tachyarrhythmias after operative repair of a secundum type atrial septal defect in adults", Am J Cardiol, 51(2), tr. 273-6.

7. J. M. Oliver, P. Gallego, A. Gonzalez và các cộng sự. (2002), "Predisposing conditions for atrial fibrillation in atrial septal defect with and without operative closure", Am J Cardiol, 89(1), tr. 39-43.

8. W. L. Henry, J. Morganroth, A. S. Pearlman và các cộng sự. (1976), "Relation between echocardiographically determined left atrial size and atrial fibrillation", Circulation, 53(2), tr. 273-9.

9. J. Wi, J. Y. Choi, J. M. Shim và các cộng sự. (2013), "Fate of preoperative atrial fibrillation after correction of atrial septal defect", Circ J, 77(1), tr. 109-15.

10. K. A. Popio, R. Gorlin, L. E. Teichholz và các cộng sự. (1975), "Abnormalities of left ventricular function and geometry in adults with an atrial septal defect. Ventriculographic, hemodynamic and echocardiographic studies", Am J Cardiol, 36(3), tr. 302-8.

11. A. J. Sanfilippo, V. M. Abascal, M. Sheehan và các cộng sự. (1990), "Atrial enlargement as a consequence of atrial fibrillation. A prospective echocardiographic study", Circulation, 82(3), tr. 792-7.

12. C. Nyboe, M. Fenger-Gron, J. E. Nielsen-Kudsk và các cộng sự. (2013), "Closure of secundum atrial septal defects in the adult and elderly patients", Eur J Cardiothorac Surg, 43(4), tr. 752-7.

13. S. Nagata, Y. Nimura, H. Sakakibara và các cộng sự. (1983), "Mitral valve lesion associated with secundum atrial septal defect. Analysis by real time two dimensional echocardiography", British heart journal, 49(1), tr. 51-58. 
14. C. A. Boucher, R. R. Liberthson và M. J. Buckley (1979), "Secundum atrial septal defect and significant mitral regurgitation: incidence, management and morphologic basis", Chest, 75(6), tr. 697-702.

15. Kieran M. Hynes, Robert L. Frye, Robert O. Brandenburg và các cộng sự. (1974), "Atrial septal defect (secundum) associated with mitral regurgitation", American Journal of Cardiology, 34(3), tr. 333-338.

16. Quang-Huy Dang, Ngoc-Thanh Le, Cong-Huu Nguyen và các cộng sự. (2017), "Totally Endoscopic Cardiac Surgery for Atrial Septal Defect Repair on Beating Heart Without Robotic Assistance in 25 Patients", Innovations:Technology and Techniques in Cardiothoracic and Vascular Surgery, 12(6), tr. 446-452.

17. Z. S. Ma, M. F. Dong, Q. Y. Yin và các cộng sự. (2012), "Totally thoracoscopic closure for atrial septal defect on perfused beating hearts", Eur J Cardiothorac Surg, 41(6), tr. 1316-9.

18. G. Liu, Y. Qiao, C. Zou và các cộng sự. (2013), "Totally thoracoscopic surgical treatment for atrial septal defect: mid-term follow-up results in 45 consecutive patients", Heart Lung Circ, 22(2), tr. 88-91.

19. C. V. Leier, J. A. Meacham và S. F. Schaal (1978), "Prolonged atrial conduction. A major predisposing factor for the development of atrial flutter", Circulation, 57(2), tr. 213-6.

20. M. J. Davies và A. Pomerance (1972), "Pathology of atrial fibrillation in man", Br Heart $J$, 34(5), tr. 520-5.

21. C. K. Silversides, S. C. Siu, P. R. McLaughlin và các cộng sự. (2004), "Symptomatic atrial arrhythmias and transcatheter closure of atrial septal defects in adult patients", Heart (British Cardiac Society), 90(10), tr. 1194-1198.

22. J. A. Vecht, S. Saso, C. Rao và các cộng sự. (2010), "Atrial septal defect closure is associated with a reduced prevalence of atrial tachyarrhythmia in the short to medium term: a systematic review and meta-analysis", Heart, 96(22), tr. 1789-97.
23. H. Uemura (2016), "Surgical aspects of atrial arrhythmia : Right atrial ablation and antiarrhythmic surgery in congenital heart disease", Herzschrittmacherther Elektrophysiol, 27(2), tr. 137-42.

24. J. M. Kalman, G. F. VanHare, J. E. Olgin và các cộng sự. (1996), "Ablation of 'incisional' reentrant atrial tachycardia complicating surgery for congenital heart disease. Use of entrainment to define a critical isthmus of conduction", Circulation, 93(3), tr. 502-12.

25. D. Henglein, B. Cauchemez và G. Bloch (1999), "Simultaneous surgical treatment of atrial septal defect and atrial flutter using a simple modification of the atrial incision", Cardiol Young, 9(2), tr. 197-9.

26. J. G. Murphy, B. J. Gersh, M. D. McGoon và các cộng sự. (1990), "Long-term outcome after surgical repair of isolated atrial septal defect. Follow-up at 27 to 32 years", N Engl J Med, 323(24), tr. 1645-50.

27. H. V. Schaff, J. A. Dearani, R. C. Daly và các cộng sự. (2000), "Cox-Maze procedure for atrial fibrillation: Mayo Clinic experience", Semin Thorac Cardiovasc Surg, 12(1), tr. 30-7.

28. Y. M. Im, J. B. Kim, S. C. Yun và các cộng sự. (2013), "Arrhythmia surgery for atrial fibrillation associated with atrial septal defect: right-sided maze versus biatrial maze", J Thorac Cardiovasc Surg, 145(3), tr. 648-54, 655 e1; discussion 654-5.

29. Hunbo Shim, Ji-Hyuk Yang, Pyo-Won Park và các cộng sự. (2013), "Efficacy of the maze procedure for atrial fibrillation associated with atrial septal defect", The Korean journal of thoracic and cardiovascular surgery, 46(2), tr. 98-103.

30. W. Wang, D. Buehler, A. M. Martland và các cộng sự. (2011), "Left atrial wall tension directly affects the restoration of sinus rhythm after Maze procedure", Eur J Cardiothorac Surg, 40(1), tr. 77-82.

31. Y. Kosakai (2000), "Treatment of atrial fibrillation using the Maze procedure: the Japanese experience", Semin Thorac Cardiovasc Surg, 12(1), tr. 44-52. 